\title{
Community composition and diversity of phytoplankton in relation to environmental variables and seasonability in a tropical mangrove estuary
}

\begin{abstract}
This paper presents the aspects of phytoplankton communities along a tropical mangrove estuary in Sarawak, Malaysia. Data were collected monthly from the study area from January 2013 to December2013 and was pooled into seasons to examine the influence of seasonality. The estuary revealed relatively species-rich, and a total of 102 species under 43 genera were recorded comprising 6 species of Cyanophyceae; 4 species of Chlorophyceae; 62 species of Bacillariophyceae and 30 species of Dinophyceae. The species composition, as well as the mean abundance (cellsL-1) of phytoplankton, were found in order of Bacillariophyceae $>$ Dinophyceae $>$ Cyanophyceae> Chlorophyceae. Mean abun-dance of phytoplankton ranged from 5694 to 88890 cellsL-1over the study period with its higher value in the dry season. Species recorded from the estuary were dominated by Pleurosigma normanii, Coscinodiscussp, Coscinodiscus centralis, Coscinodiscus granii, Dinophysis caudata, Ceratium carriense, Ceratium fusus, and Ceratium lineatum. Abundance of phytoplankton demonstrated positive correlation with chlorophylla( $\mathrm{r}=0.69)$, ammonium $(r=0.64)$ and silica $(r=0.64)$. Significant differences (ANOSIMand nMDS) were observed in the species community structure between intermediate and the wet season. Canonical correspondence analysis (CCA) showed that most of the species assemblages were positively correlated with surface water temperature, salinity, $\mathrm{pH}$, ammonium and nitrate in the intermediate and dry season towards larger species composition in the respective seasons whereas silica showed influence on the species assemblage in the wet season. The findings suggest that the Sibuti mangrove estuary is productive in terms of diversified phytoplanktons and their variability in assemblage, those are influenced by the hydrological and biological factors.
\end{abstract}

Keyword: Phytoplankton community; Environmental variables; Seasonality; Tropical mangrove estuary 